\title{
DIMENSI PELAYANAN PASTORAL
}

\author{
Pdt.Sadrak Kurang1
}

\begin{abstract}
Abstrak
Pelayanan Penggem6alaan merupakan satu tanggung jawa6 yang diberikan Tuhan Yesus Kepada yang dipercayainya selaku gembala, namun pemahaman di antara para gembala masa kini tentang tanggung jawab itu semakin Kabur dengan Kebanyakan hanya mejalankan fungsi penggembalaan setengah jadi. Itu se6abnya dalam penelitian pastoral di antara beberapa gereja pada tahun silam ditemui adanya sejumlah Kelemahan Kefidupan Keimanan jemaat. Gembala bertanggung jawa6 mengajar (dodaskalous), menuntun (piomenas) dan memimpin (episkopos). Ketiganya tidakterpisahkan melainkan menyatu dan tersinergi dalam sepanjang Kegiatan pastoral seperti yang telah ditunjukKan oleh Yesus Kristus dalam menggembalakan muridSNya. Menggem6alakan umat Tuhan sesungguhnya adalah pelayanan Tuhan Yesus yang Ia sharing-kan kepada para gem6ala jemaat. Kalau engkau mengasihi Aku, Kata Yesus, gembalakanlah domba-dombaKu. Yoh. 21:15-19.
\end{abstract}

\section{A. PENDAHULUAN}

Hasil-hasil pengamatan di lapangan telah menunjukkan bahwa banyak jemaat lokal telah "panas pun tidak, dingin pun tidak". Lalu ditelusuri lebih mendalam, ternyata para gembala kebanyakan kebingungan dalam menghadapai jemaat modern saat ini. Kehidupan masyarakat modern tidak dapat dihindari dan sebab itu tidak sedikit anggota jemaat yang pernah diteliti itu menghidupi kehidupan yang tidak sepadan dengan kebenaran Firman Tuhan. Pada sisi yang lain, terdapat juga indikasi kuat bahwa kebanyakan gereja yang pernah diobservasi, anggota jemaatnya, dan majelis gereja berkonflik dengan gembala jemaat. Fakta menunjukkan bahwa gembala jemaat banyak yang diminta meletakkan jabatannya selaku jemaat bukan saja karena kasus moral tetapi karena ketidaksanggupannya memimpin jemaat itu maju dan bertumbuh dewasa.

Lebih jauh lagi, telah terlihat fenomena di jemaat adanya apa yang saya sebut sebagai 'konversi internal eklesiastis'. Artinya bahwa akhir-akhir ini telah banyak anggota-anggota jemaat lokal satu denominasi telah berpindah anggota ke denominasi gereja lain. Seorang pengkhotbah terkenal pernah dikritik oleh sekelompok pemimpin gereja aliran lain daripadanya. Kritikannya adalah bahwa pengkotbah itu adalah "pencuri domba". Artinya bahwa pengkhotbah tersebut telah meraup banyak anggota dari gereja para pemimpin itu tadi. Beberapa saat kemudian setelah si pengkhotbah itu mendengar kritikan tajam tersebut ia lalu menjawab bahwa, "ia bukan pencuri domba, melainkan domba (anggota jemaat) yang berpindah itulah yang datang sendiri ke gereja kami mencari rumput segar". Fenomena perpindahan anggota itu bila ditelusuri penyakitnya terdapat di tangan pemimpin gereja khususnya sang gembala jemaat.

\footnotetext{
${ }^{1}$ Dosen Tetap STT Jaffray Makassar.
} 
Fakta lain, bahwa sekali waktu seseorang pernah bertanya kepada seorang gembala muda yang baru saja menammatkan studinya pada salah satu sekolah tinggi teologi dengan pertanyaan tentang apa yang ia ingin kerjakan sebagai seorang gembala jemaat yang baru di gereja itu. Jawaban gamblang yang dikemukakan gembala muda itu adalah bahwa ia ingin membangun sebuah gedung gereja yang lebih bagus dibanding dengan yang ada sekarang. Jawabannya itu sah-sah saja, namun bila dikaji secara matang berdasarkan landasan pijak ilmu penggembalaan maka jawaban itu menunjukkan bahwa ia bukan seorang gembala jemaat yang mengenal tugas penggembalaan. Gembala pada dasarnya berurusan dengan yang digembalakan yakni manusia, kawanan domba Allah, suatu umat gembalaan dan bukannya gedung walaupun gedung merupakan salah satu aspek yang juga patut berada dalam lingkup perhatian gembala jemaat. Pembangunan gedung bukan tugas utamanya melainkan bagian tugas yang dapat dipercayakan kepada anggota jemaat.

Dari penemuan fakta dan fenomena kasus diatas maka pertanyaan selanjutnya ialah apakah gembala-gembala itu tidak diberi pengajaran bagaimana seharusnya ia menggembalakan? Jawabannya adalah bahwa dari penelitian² yang diadakan selama ini terbukti umumnya gembala hanya melaksanakan tugas rutin berkhotbah dan dewasa ini kebanyakan waktu para gembala sangat diluangkan hanya untuk pelayanan berkhotbah itu.

Berdasarkan fakta itu maka penulis bermaksud menguraikan tiga tugas utama (peran utama) penggembalaan yang perlu diatur dan diintegrasikan demi pencapaian tujuan penggembalaan jemaat. Tujuan akhir dari uraian ini adalah.

1. Peserta diharapkan dapat lebih disegarkan kembali dalam memahami tugas gembala yang berdimensi tiga untuk kemudian.

2. Para gembala jemaat mengaplikasikan pengetahuannya itu agar lebih berfokus kepada ketiga peran itu secara menyeluruh, serta,

3. Majelis dan Jemaat diharapkan juga dapat memahami peran itu untuk kemudian lebih mendorong dan bekerja sama dengan gembala masing-masing dalam pelayanan gembalanya.

Sumber utama materi pokok bahasan ini ditemukan dari fakta di gereja lalu diuraikan berdasarkan kebenaran alkitab sebagai jawaban atas fakta lapangan itu. Adapun ketiga tugas utama gembala yang disebutkan pada topik diatas sebagaimana dibahas dalam seminar ini, adalah gembala jemaat sebagai: pengajar (gembala pengajar), penuntun (gembala pembina), dan penilik (gembala pemimpin).

\footnotetext{
${ }^{2}$ Kebanyakan penelitian itu diadakan mahasiswa program stratum 2 (S2) STTJ. Lapuran penelitian tsb umumnya dikembangkan menjadi tulisan karya ilmiah mereka.
} 


\section{B. PERAN GEMBALA JEMAAT}

Pada dasarnya tugas seorang gembala sebagaimana dapat ditemukan didalam Alkitab sangat variatif. Berbagai tugas itu bila dilihat dari pengertian kata gembala secara etimologis banyak kali ditemukan dalam bentuk analog-simbolis sehingga kadang kala kata itu dipakai menunjuk Tuhan sebagai gembala bagi Israel, umatnya di Perjanjian Lama. Itu misalnya yang terdapat dalam ungkapan Mazmur 23, “Tuhan adalah Gembalaku, aku tak akan kekurangan suatu apapun”. Konsep yang sama dipakai oleh Yohanes di Perjanjian Baru saat ia mengutip perkataan Yesus Kristus yang berkata, "Akulah Gembala yang baik...". Namun sebaliknya kata ini kerap pula dipakai dalam bentuk harfiah yang menunjuk kepada seorang gembala hewan yakni gembala kawanan domba peliharaan, seperti Yakub, Musa dan juga Daud yang pernah menekuni profesi gembala seperti itu. Kata gembala dalam pengertian kiasan diatas itulah dipakai menunjuk kepada seseorang yang mengerjakan pelayanan gereja. Tugas dan tanggung jawabnya gembala sebagaimana yang diungkapkan alkitab adalah antara lain: mendoakannya (Yoh.10), memberi makan (Lukas 17: 7, dll); menjalankan kekuasaan (Wahyu 12:5, dll); membela dan menjaga (Mat. 9:36, dll); memelihara (Ibrani 13:10, dll); mengatur dan mengawasi (Titus 1:2-5, dll); mencari dombanya yang hilang (Lukas 15:1 dst, dll); menuntun dombanya keluar dan masuk kandangnya kembali (Yoh.10, dll); melindungi dombanya dari bahaya (Maz. 23, dll).

Bila dilihat pada pemakaian istilah gembala yang dikenakan kepada pekerjaan pelayanan gereja, maka konsep tugas dan tanggung jawab itu diserap dan didasarkan atas fakta pekerjaan-pekerjaan gembala hewan di tanah Isreal zaman dulu. Dengan mengumpul pemahaman-pemahaman makna dasar kata tersebut dalam suatu pengertian baik dari pemikiran harfiah maupun analog/kiasan maka tugas dan tanggung jawab seorang gembala jemaat dapat terbagi kedalam tiga kategori peran sebagai berikut:

\section{PENGAJAR}

Seorang gembala jemaat disebut didalam alkitab sebagai seorang "gembala-pengajar" yang diambil dari kata bahasa Yunani poimenas didaskalous, yang istilah itu didalam bahasa Ibrani adalah Rabbi. Kata rabbi dipakai berulang kali di Injil-injil sinoptik dalam menyebut Yesus tatkala ia mengajar umat Israel baik di rumah rumah sembayang, di bait suci maupun di alam terbuka. Ia mengajar dengan penuh kuasa dan hikmat yang saat itulah ia kemudian dipanggil rabbi. Konsep mengenai gembala-pengajar lebih jelas dipakai oleh Rasul Paulus pada waktu ia menjelaskan teologi gereja (ekklesiologi) didalam suratnya kepada jemaat di Efesus (Efesus 4 dan 5). Di dalam pasal 4:11-12, 
Paulus mengungkapkan adanya beberapa petugas atau pengerja gereja sebagai pelayan yang bertugas dan bertanggung jawab memperlengkapi atau melatih orang-orang kudus (gereja) bagi pekerjaan pelayanan pembangunan tubuh Kristus. Mereka itu antara lain: rasul-rasul, nabi-nabi, penginjilpenginjil, gembala dan pengajar.

Dengan mengamati isi Efesus 4 diatas, akan diperoleh lima jenis pekerjaan dan jabatan yakni rasul, nabi, evangelis, gembala dan pengajar. Namun kalau dikaji dengan menguraikannya dari sudut sintaksis ${ }^{3}$ bahasa Yunani, maka dari dalam teks ini hanya akan diperoleh empat jenis pekerjaan dan jabatan yakni, rasul, nabi, evangelis dan gembala-pengajar. Mengapa?

Bahasa Yunani sama seperti bahasa Eropa lainnya, memiliki dua jenis kata sandang yakni kata sandang defenitif (definite article) dan kata sandang indefenitif (indefinite article). Kata sandang defenitif ialah ton, tou ataupun tous yang dapat diterjemahkan kedalam bahasa Inggris dengan kata sandang, the. Daftar tugas dan jabatan gerejani dalam Efesus itu masing-masing didahului oleh kata sandang defenitif, tous, yang artinya sesuatu yang jamak dan defenitif. Dari kelima daftar pekerjaan itu hanya empat dari kata tersebut mempunyai kata sandang defenitif, sedang yang satu lainnya tidak didahului oleh satupun kata sandang kecuali oleh kata penghubung kai yang terjemahannya adalah 'dan'. Ayat ini dalam bahasa Yunani tertulis "...Kai autos hedoke tous men apostolous, tous de prophetas, tous de euanggelistas, tous de poimenas kai didaskalous." Perhatikan kata kata yang bergaris bawah sebab justru kata itulah yang dimaksudkan dalam uraian sintaksis memiliki pengaruh terhadap pengertian yang membentuk pikiran tersebut diatas. Bila ayat itu kemudian ditafsir berdasarkan rumusan sintaksis bahasa Yunani, dua kata terakhir yakni gembala dan pengajar yang hanya memiliki satu kata sandang defenitif, maka dapat ditarik kesimpulan bahwa keduanya memiliki dua makna berbeda yang dikerjakan oleh satu pengerja saja. Keduanya disatukan dan tidak mengandung dua pikiran. Jadi pengertiannya adalah bahwa gembala jemaat adalah seseorang yang mengerjakan pekerjaan gembala dan sekaligus berkemampuan mengajar. Sama seperti apa yang dibuat Yesus tatkala masih bersama muridnya di bumi, Ia menggembalakan mereka dan sambil menemani muridnya ia tiada hentinya mengajar mereka sekaligus mengajar masyarakat lainnya. Jadi menurut rasul Paulus, gembala tidak hanya melayani sebagai gembala dalam arti menuntun, menghibur,dan lain sebagainya melainkan dipanggil untuk mengajar.

Berangkat dari Efesus 4:11-12, tugas utama yang ditekankannya adalah mengajar. Mengajar adalah salah satu pelayanan gembala yang vital oleh sebab terdapat cukup banyak orang tidak berpeluang duduk dalam sebuah pertemuan kelas, yang orang-orang

\footnotetext{
${ }^{3}$ Sintaksis= ilmu tata kalimat, dalam hal hubungan kata dengan kata lainnya atau kalimat dengan kalimat lainnya dalam satu teks.
} 
itu pada dasarnya memerlukan kebenaran yang jelas, pasti dan teguh dari Tuhan. Paulus sebagai rasul pernah menetap di Efesus dan menggembalakan jemaat yang dibangunnya itu selama tiga tahun lamanya. Ia mengajar mereka tentang kebenaran Firman Tuhan dan pada saat masanya ia harus meninggalkan Efesus, menugaskan Timotius anak asuhnya yang telah ia kaderkan melanjutkan tugas penggembalaan jemaat Efesus. Itu sebabnya ia menasehati Timotius agar "tekun membaca kitab-kitab suci, tekun membangun dan tekun mengajar" (I Timotius 4: 13.). Hal yang sama ia anjurkan kepada salah seorang kadernya yang lain yakni Titus yang ia tinggalkan di Krete untuk menggembalakan jemaat disana. Ia menganjurkannya agar mengajarkan ajaran yang sehat, (Titus 2:1). Mengajar merupakan bagian dari pelayanan pemberian makan bagi domba yang pada hakekatnya adalah makanan rohaniah. Sebab itu, baik Yesus maupun Paulus dkk., selaku gembala pengajar, mereka menyelenggarakan panggilan pelayanan mengajar dalam beberapa bentuk antara lain, berkhotbah, memimpin diskusi kelompok kecil yang membahas kebenaran rohaniah, dialog pribadi menyangkut kebenaran dalam kaitan kehidupan, soal jawab, dan pengajaran langsung berupa pembimbingan dan observasi partisipatif. Karena itulah tugas ini merupakan tugas pemeliharaan dalam hal memperkuat pendirian iman anggota jemaat agar terlindung dari bahaya ancaman penyesatan dari ajaran iman yang sehat.

\section{PENUNTUN}

Salah satu contoh kasus dalam bidang pelayanan gembala penuntun, misalnya adalah bila salah satu dari anggota jemaat gembalaannya berada dalam keadaan sakit. Dalam kasus itulah seorang gembala jemaat menjalankan perannya selaku "gembala penuntun" atau apa yang disebut oleh Carl George sebagai "topi kedua penggembalaan"4. Istilah yang dipakai didalam bahasa Yunanai untuk tugas ini adalah poimen yang didalam bahasa Inggris adalah shepherd. Kita menerjemahkannya dengan kata "gembala". Oleh karena demi membedakan tugas ini dengan dua peran lainnya maka dipakailah ungkapan 'gembala-penuntun'.

Saat kata ini dipakai menunjuk kepada Tuhan (Maz. 23) dan Yesus Kristus (Yoh. 10 dan Ibrani 13:20) hal itu dimaksudkan guna mengungkapkan pekerjaan Tuhan Allah dan Yesus sebagai penuntun jalan di kehidupan keseharian disini dan kini terutama dalam kehidupan batniah atau rohaniah (inner and spiritual life). Itulah yang ditulis Petrus dalam kalimat, "sebab dahulu kamu sesat seperti domba, tetapi sekarang kamu telah kembali kepada gembala dan pemelihara jiwamu" (I Petrus 2: 25). Kehidupan batiniah memang perlu penguatan dan perlengkapan dalam menghadapi gelombang kehidupan yang serba berganti dengan cepat, rumit dan kadang kala sulit. Agar seseorang

\footnotetext{
${ }^{4}$ Carl F George, Leading \&Managing Your Church, Fleming Revell, Grand Rapids MI , 1993, 14.
} 
bisa mengambil keputusan tepat demi tindakan benar dalam kegelapan hidup, dan atau agar dapat terbebas dari belenggu beban hidup yang menindis maka diperlukan seorang penolong, penuntun jalan terang. Disinilah peran Tuhan selaku gembala. Daud dalam pengalamannya menyaksikannya sehingga ia bernyanyi : "Tuhan adalah gembalaku, takkan kekurangan aku. Ia membaringkan aku di padang yang berumput hijau, Ia membimbing aku ke air yang tenang; Ia menyegarkan jiwaku, Ia menuntun aku di jalan yang benar..., Sekalipun aku berjalan dalam lembah kekelaman aku tidak takut bahaya sebab Engkau besertaku..." (Maz. 23:1-4).

Konsep peran gembala seperti diatas menjadi landasan berpijaknya pemikiran Yesus Kristus tatkala ia bercakap dan menasehati Petrus sebagaimana yang dikutip Yohanes didalam Injil Yohanes 21:15-19. Disitu Petrus ditanya oleh Yesus tiga kali dengan pertanyaan yang sama, “...apakah engkau mengasihi Aku?" kata Yesus. Jawaban Petrus juga tiga kali dengan kalimat berita yang sama, "Benar Tuhan, Engkau tahu, bahwa aku mengasihi Engkau. " Selanjutnya, berangkat dari jawaban itu Yesus memberi amanah kepadanya, (kalau engkau mengasihi aku) "gembalakanlah domba-dombaku". Dalam tiga kali pemberian amanah itu Yesus menggunakan dua kata Yunani yang berbeda namun mengandung pengertian yang sama. ${ }^{5}$ Pada amanah pertama dan ketiga Yesus memakai kata Yunani Boske yang artinya 'berilah dombaku makan', sedang pada amanah kedua, kata gembalakan itu adalah poimenas yang berarti 'tuntunlah atau bimbinglah, atau rawatlah domba-dombaKu'. Pertanyaan yang dapat kita kemukakan kepada teks ini ialah mengapa (dalam bahasa Yunani itu) Yesus memakai dua kata yang berbeda lalu diterjemahkan sama arti? Dan dengan demikian apa pula artinya?

Petrus dipaggil sebagai rasul dan gembala. Ia menggembalakan umat Tuhan dengan dasar mengasihi mereka dan bukan karena motivasi lainnya.Hal mengasihi Dia adalah dasar penyelenggaraan penggembalaan sebab didasarkan atas pemahaman bahwa Yesus telah membeli umatNya itu dengan darah dan hidupNya sendiri. Dalam hal ini termasuk Petrus juga terlibat didalamnya sebagai umat yang telah lebih dahulu dikasihiNya. Jadi karena Petrus telah lebih dahulu mengalami kasih Tuhan Yesus maka ia diminta untuk juga turut mengasihi dengan ujud menggembalakan jemaat Tuhan yang dikasihi olehNya. Dalam menggembalakan itu dua tugas sekaligus dijalankan secara bersamaan yakni mengajar dan menuntun jemaat Tuhan. Jadi dalam pengungkapan Yesus yang kedua kalinya dengan menggunakan kata poimen atau shepherd adalah bahwa ia merujuk pada pekerjaan penggembalaan dalam hal gembala memberi makan, memelihara, memimpin guna penumbuhan dalam iman, menuntun mereka ke dan di jalan yang benar, melawat,

\footnotetext{
${ }^{5}$ Didalam alkitab bahasa Indonesia ketiganya menggunakan kata yang sama, yakni "gembalakanlah'
} 
mendukung, memotifasi, mendorong, menghibur, menguatkan hati, membimbing dan lain sebagainya.

Jadi pada dasarnya tugas gembala penuntun itu dikerjakan dalam berbagai subyek pelayanan seperti dalam menuntun jemaat beribadah dan menyembah Tuhan, melaksanakan proses pernikahan anggota jemaat, penghiburan yang susah dan atau berduka, dan pemakaman yang meninggal dunia, mengunjungi dan mendoakan yang sakit dan lemah, membimbing mereka yang mengalami problem dan menolong mencarikan jalan keluarnya.

\section{PEMIMPIN-MANAJER.}

Kalau kita mengamati pelayanan Yesus Kristus kepada muridnya, Ia tidak hanya mengajar dan menuntun mereka, tetapi juga memimpin mereka dengan Ia menginformasikan serta menunujukkan kepada mereka bagaimana Ia memimpin dan mengatur mereka dalam pelayanan murid-murid sambil tetap berada dalam pengawasanNya. Ia mengatakan kepada mereka bahwa Ia datang untuk melayani (Mat. 20:28) dan lalu Ia meminta mereka agar seperti Dia dalam pelayanan selaku guru dan pemimpinnya. Ia katakana "barangsiapa yang ingin menjadi besar hendaklah Ia menjadi pelayan (Mat.20:26). Lebih dari itu Yesus memberikan mereka peribagaimana Ia melayani mereka selaku pemimpin para murid itu dengan jalan Ia membasuh kaki muridnya (Yoh. 13: 1-17). Inilah yang pada masa kini disebut pemimpin-pelayan.

Dr. R.Sessoms ${ }^{6}$ menyimpulkan hasil penelitiannya selama 21 tahun di berbagai gereja, seminary dan organisasi-organisasi gereja lainnya, di beberapa Negara dengan mangatakan bahwa apa yang ia temukan sekarang ini adalah keperluan yang sangat mendesak akan adanya pemimpin gereja yang berkualitas. Ia mengungkapkan hasil penelitiannya dengan mengatakan bahwa, ada banyak gembalagembala yang sangat baik dan terampil berkhotbah, namun gagal memimpin gereja. Mereka tidak memobilisasi gerja untuk bergerak melayani. Banyak orang awam yang memiliki kemampuan memimpin meninggalkan gerejanya karena mereka tidak dapat mentoleransi gerakan pelayanan yang tidak dijalankan sebagaimana mestinya kecuali diatur dengan baik. Sebab itulah ia tulis: “...nothing is more important for the $21^{\text {st }}$ century church than leadership...", (yang sangat diperlukan gereja abad 21 adalah kepemimpinan).

Gembala adalah seorang pemimpin dalam arti sesuai yang dimaksudkan oleh Carl George (1993) dan oleh Peter Wagner (1995) adalah seorang equipper, atau orang yang memperlengkapi, atau pemimpin-pelengkap.7 Apa maksudnya? Kata yang dipakai penulis-penulis Perjanjian Baru dalam bahasa Yunani untuk menunjuk kepada maksud ini adalah kata episkopos, yang dalam bahasa

\footnotetext{
${ }^{6}$ Seorang dosen dan mantan gembala jemaat Alliance Church di New York dan pernah mengajar di STTJ Makassar. Ia menulis hasil risetnya ini pada catatan kuliah kepemimpinan di STTJ beberapa tahun silam.

${ }^{7}$ Carl F George, 1993, hal. 7; Peter Wagner, Memimpin Gereja Anda Bertumbuh, Harvest Pub. House, 1995, 83-84.
} 
Indonesia adalah 'penatua atau penilik jemaat'. Didalam struktur pemerintahan gereja sekarang penatua, dikenal dengan istilah 'majelis gereja'. Diantara majelis gereja disitulah tergabung gembala jemaat. Majelis gereja adalah kelompok pimpinan gereja lokal yang menjalankan tugas pengatur dan penilik yang dapat kita samakan dengan istilah sekuler yaitu manajer, ataupun dewan pimpinan. Mengapa gembala adalah juga penatua gereja?

1. Dari pengalaman rasul Petrus dapat ditemukan pernyataannya bahwa disamping ia adalah seorang rasul dan gembala, ia juga mengatakan bahwa ia adalah penatua atau penilik jemaat. Hal ini dikemukakannya didalam suratnya pada I Pterus 5:1, "Aku menasehatkan para penatua di antara kamu, aku sebagai rekan penatua dan saksi penderitaan Kristus..." Jadi tidak ditutup kemungkinan bahwa sama seperti Petrus adalah gembala, maka ia juga sekaligus adalah anggota penatua jemaat. Mungkin saja bahwa Petrus lah yang menjadi pimpinan para penatua itu.

2. Arti literal kata episkopos adalah penilik, yang didalam Septuaginta mempunyai arti 'superintenden' (Bilangan 4:16; 31:14). Memperhatikan Kisah rasul 20 disitu dapat ditemukan keterangan adanya indikasi bahwa penatua, penilik dan gembala adalah tiga kata yang pada hakekatnya dijabat oleh orang-orang yang sama. Artinya pelayanan penggembalaan dikerjakan oleh penatua (presbutros) yang juga adalah penilik (episkopos). Dikatakan, "karena itu ia menyuruh seorang dari Miletus ke Efesus dengan pesan supaya penatua jemaat datang ke Miletus. Sesudah mereka datang, berkatalah ia kepada mereka...,...jagalah dirimu dan jagalah seluruh kawanan, karena kamulah yang ditetapkan Rohkudus menjadi penilik untuk menggembalakan jemaat Allah yang diperolehnya dengan darah anakNya sendiri." (Kis rasul 20: 17, 28).

Berdasarkan keterangan diatas gembala jemaat adalah salah seorang dari anggota badan pimpinan gereja lokal yang menjalankan fungsi kepemimpinannya selaku penilik dan pengatur. Itu sebabnya rasul Paulus mengamanatkan Titus sebagai gembala jemaat di Krete agar ia "mengatur apa yang masih perlu diatur dan menetapkan penatua-penatua di setiap kota,...(Titus 1:5). Dua tanggung jawab tersebut dalam hal ini mengatur dan menetapkan menunjukkan pelayanan gembala selaku pemimpin dan pengatur. Definisi yang dikemukakan oleh Wagner dalam hal gembala sebagai pemimpin-pelengkap adalah dengan mengatakan bahwa "seorang pelengkap ialah seorang pemimpin yang secara aktif membuat tujuan-tujuan bagi jemaatnya menurut kehendak Allah, memperoleh hak kepemilikan tujuan-tujuan itu dari jemaatnya, dan memastikan setiap anggota gereja mempunyai motivasi yang benar serta dilengkapi untuk melaksanakan bagian supaya tujuan-tujuan itu tercapai. ${ }^{8}$ Gembala jemaat bertugas menjadi pemimpin yang tidak hanya berkhotbah dan membimbing melainkan juga pelatih (equipper), yang melatih dan melengkapi setiap anggota jemaatnya dalam

\footnotetext{
${ }^{8}$ Wagner, Ibid, 83.
} 
melaksanakan tugas pekerjaan pelayanan yang dipercayakan kepada mereka masing-masing. Dengan demikian gembala jemaat tidak akan menjadi "pelaku sendiri (single fighter) pelayanan melainkan melayani bersama dengan semua anggota tubuh Kristus. Didalam hal inilah ia memobilisasi setiap jemaat bergerak kearah tujuan atau visi yang telah dicanangkannya bersama umat dan majelis gerejanya.

Gembala disebut sebagai pemimpin dan bukan yang dipimpin oleh sekelompok pimpinan gereja. Ia memimpin kelompok pimpinan itu untuk menetapkan haluan visi dan misi gereja lokal. Ia pun bersama pemimpin gereja melatih dan memperlengkapi anggota jemaatnya untuk jemaat itu membangun jemaat (Efesus 4:11-12). Jadi gembala memimpin anggota pimpinan (presbotros/episkopos) untuk anggota melayani dan bersama mencapai target dan visi gereja lokal yang telah disepakati bersama. Gembala adalah pemimpin jemaat yang bekerja degan rekan pimpinan lainnya dan bekerja bersama anggota jemaatnya. Kalau ia bekerja sendirian maka ia akan gagal dalam pencapaian tujuan dan target atau visi gereja itu.

\section{BEBERAPA POKOK PIKIRAN:}

1. Tugas seorang gembala jemaat sangat variatif karena menyangkut tanggung jawab kepada Tuhan, menyangkut kehidupan lembaga gereja itu sendiri dan menyangkut usaha memperhatikan dan mengawasi pergumulan kehidupan setiap anggota dari jemaat lokal itu sendiri. Tanggung jawab itu dipikulkan Tuhan yang kepadaNyalah gembala mempertanggungjawabkan pekerjaannya itu. Dari berbagai macam keragaman tugasnya, pekerjaan gembala dikategorikan kedalam tiga kategori peran utama yang disebut: gembala-pengajar (preacher), gembala-penuntun (shepherd) dan gembala-pemimpin. (leader-manajer).

2. Gembala-pengajar: Gembala berperan sebagai pengajar kebenaran firman Tuhan/ajaran iman yang sehat, dalam beberapa bentuk seperti berkhotbah, memimpin kelompok penyelidikan alkitab, soal jawab pribadi tentang kehidupan dan kebenaran, dan pembimbingan. Tujuannya adalah agar jemaat terpelihara dewasa dan Tuhan dimuliakan.

3. Gembala-penuntun: Gembala berperan bagai seorang ibu yang menuntun anak kandungnya dalam segala aspek untuk kemudian anak itu biasa bertumbuh dan berhasil mengatasi pergumulan hidupnya setiap hari. Bentuk pekerjaan gembala dalam hal ini adalah antara lain memimpin jemaat beribadah dan menyembah Tuhan, menguatkan bila mereka lemah, mendoakan saat mereka memerlukan tangan Tuhan, mengunjungi mereka yang sakit dan lemah, menikahkan 
anggota jemaat yang siap menikah, menghiburkan yang susah dan berduka, dan menyampaikan berkat Tuhan atas jemaatnya.

4. Gembala-pemimpin: Dalam tugas ini gembala menjalankan tugas manajerial. Ia bersama dengan anggota pemimpin gereja lainnya (majelis gereja) memperlengkapi setiap anggota jemaat untuk melaksanakan tugas pelayanan jemaat dalam membangun jemaat. Ia memimpin, menetapkan angota penatua lainnya dan bersama mereka ia, mengatur dan menetapkan hal-hal yang akan dicapai dan dikerjakan oleh jemaat. Ia mengawasi dan memobilisasi mereka untuk mencapai target dan visi gereja lokal.

5. Gembala jemaat dalam pelayanannya berdimensi tiga pelayan yang melayani selaku pemimpinpelayan sama seperti apa yang dikerjakan Yesus Kristus dalam masa pelayanannya terhadap muridnya semasa Ia di bumi.

\section{PENUTUP:}

Gembala bertanggung jawab mengajar (dodaskalous), menuntun (piomenas) dan memimpin (episkopos). Ketiganya tidak terpisahkan melainkan menyatu dan tersinergi dalam sepanjang kegiatan pastoral seperti yang telah ditunjukkan oleh Yesus Kristus dalam menggembalakan muridnya. Menggembalakan umat Tuhan sesungguhnya adalah pelayanan Tuhan Yesus yang Ia sharingkan kepada para gembala jemaat. Kalau engkau mengasihi Aku, kata Yesus, gembalakanlah dombadombaKu. Yoh. 21:15-19. Selamat melayani.

\section{Endnotes:}

${ }^{1}$ Dosen Tetap STT Jaffray Makassar.

${ }^{2}$ Kebanyakan penelitian itu diadakan mahasiswa program stratum 2 (S2) STTJ. Lapuran penelitian tsb umumnya dikembangkan menjadi tulisan karya ilmiah mereka.

${ }^{3}$ Sintaksis= ilmu tata kalimat, dalam hal hubungan kata dengan kata lainnya atau kalimat dengan kalimat lainnya dalam satu teks.

${ }^{4}$ Carl F George, Leading \&Managing Your Church, Fleming Revell, Grand Rapids MI, 1993, 14.

${ }^{5}$ Didalam alkitab bahasa Indonesia ketiganya menggunakan kata yang sama, yakni "gembalakanlah'

${ }^{6}$ Seorang dosen dan mantan gembala jemaat Alliance Church di New York dan pernah mengajar di STTJ Makassar. Ia menulis hasil risetnya ini pada catatan kuliah kepemimpinan di STTJ beberapa tahun silam.

${ }^{7}$ Carl F George, 1993, hal. 7; Peter Wagner, Memimpin Gereja Anda Bertumbuh, Harvest Pub. House, 1995, 8384.

8 Wagner, Ibid, 83. 


\section{KEPUSTAKAAN}

Adams, Jay E. Shepherding God's Flock. Baker Book House, Grand Rapids. MI, USA, 1981.

Anderson, Leith. A Church for The 21st Century. Bethany House, Pub. Mineapolis Minnesota, USA. 1992.

Art van Beek. Pendampingan Pastoral. BPK Jakarta. 2001.

Dictionary of Practical Theology. $8^{\text {th }}$ ed. S.v "Pastoral”. By Franklin Pascall and Herschel Hobbs.

Hommes, Tjaard G dan Gerrit Singgih. Teologi dan Praksis Patoral. BPK Jkt dan Kanisius, Jogyakarta. 1994.

Sadrak Kurang. "Hubungan Timbal Balik Penggembalaan dengan Pertumbuhan Gereja di Beberapa Gereja di Makassar dan Kaltim." Lapuran Penelitian STT Jaffray 2002-2003.

Sessoms< Richard. "Kepemimpinan Gereja". Makalah/Bahagian dari Dissertasi Ph.D di Fuller Seminary, disajikan pada kuliah S2, STT Jaffray.2001.

George, Carl F. Leading and Managing Your Church. Fleming Revel, Grand Rapids, USA. 1993.

Wagner, Peter. Your Church Can Grow. Regal Books, Glandale,CA. 1979. Memimpin Gereja Anda Bertumbuh. Harvest Pub. House. Terjemahan. 1995. 